\title{
Thermal neutron absorption in printed circuit boards
}

\author{
Simon P. Platt, Member, IEEE, Shaun August, Michael MacLeod, Michael J. Anderson, David Cheneler, \\ Stephen D. Monk
}

\begin{abstract}
Measurements and simulations of thermal neutron attenuation by printed circuit boards are compared. Attenuation coefficients in typical epoxy-resin/glass-fibre substrate material can be as high as $2 \mathrm{~cm}^{-1}$, corresponding to $27 \%$ attenuation by $1.6 \mathrm{~mm}$ of substrate. Attenuation is attributed to neutron scattering off hydrogen in the resin acting in synergy with absorption by boron in the glass; this effect is substantially greater than that estimated from absorption by boron alone. Design of thermal neutron detector assemblies should take this attenuation into account and may require board thickness to be minimised or specialised substrate materials to be used.
\end{abstract}

Index Terms-Neutrons, Printed circuits, Reactor instrumentation

\section{INTRODUCTION}

Neutron instrumentation for applications such as decommissioning the Primary Containment Vessel and housing areas within the Fukushima Daiichi Nuclear Power Plant requires a compact format. We are developing such instruments using semiconductor detectors fabricated from silicon carbide with boron carbide converter layers [1]. One such configuration uses a three-dimensional multilayer design to increase sensitive volume with arrays of detectors in inner and outer circuit boards; detectors in inner layers are surrounded by outer layers which tend to attenuate the neutron field being measured.

Boron is present in most circuit boards, including those based on the widely used class of epoxy-resin/glass-fibre composites designated FR-4 ("FR" signifying "flame-retardant", FR-4 being a particular class of flame-retardant materials sonamed in the 1960s by the National Electrical Manufacturers Association, NEMA, and which has since become ubiquitous [2]). The effect of neutron absorption by boron in circuit board substrate materials including FR-4 has been known for some time, but little studied, and with the development of complex assemblies for detecting thermal neutrons using multiple printed-circuit substrates it can become significant.

In this paper we investigate thermal neutron attenuation in circuit board substrate materials using measurement and simulation.

Manuscript received September 30, 2020; revised January 22, 2021 and February 16, 2021

This work is supported by the UK Engineering and Physical Sciences Research Council, grant reference EP/S020411/1, and is part of the UK Japan Civil Nuclear Research Programme. MCNP simulations were done on the High End Computing facility at Lancaster University.

S. P. Platt, M. J. Anderson, D. Cheneler and S. D. Monk are with the Department of Engineering, Lancaster University, Lancaster, LA1 4YW.

S. August, M. MacLeod and M. J. Anderson are with Innovative Physics Ltd., Landguard Manor, Landguard Manor Road, Shanklin, Isle of Wight, PO37 7JB.

\section{A. Printed circuit substrate composition}

Most circuit board substrate materials, including FR-4, contain boron; most notably the glass fibres commonly used for reinforcement typically incorporate between $5 \%$ and $10 \%$ by weight of boron trioxide $\left(\mathrm{B}_{2} \mathrm{O}_{3}\right)$ [3], [4], corresponding to a boron content of between $1.55 \%$ and $3.1 \%$ by weight and a ${ }^{10} \mathrm{~B}$ content of between $0.29 \%$ and $0.57 \%$, assuming natural boron.

The precise composition of FR-4 epoxy resins is variable and proprietary. The principal components of the resin in most FR-4 substrates are understood to be carbon, hydrogen, oxygen and bromine. Zaffora and Magistris [5] give formulae $\mathrm{C}_{18} \mathrm{H}_{24} \mathrm{O}_{3} \mathrm{Br}_{4}$ and $\mathrm{C}_{18} \mathrm{H}_{24} \mathrm{O}_{3}$ for brominated and unbrominated resins, respectively. Bromine is used as a fire suppressant and "non-halogenated" substrates typically incorporate phosphorous or aluminium compounds into the resin for the same purpose. Nitrogen is often present for example from dicyandiamide curing agents. Boron can also be present [6], [7]; indeed, Mullins et al. [7] describe boric acid $\left(\mathrm{H}_{3} \mathrm{BO}_{3}\right)$ as being up to $1 \%$ by weight, corresponding to a maximum ${ }^{10} \mathrm{~B}$ content in the resin of about $0.03 \%$ by weight. Ceramic and other inorganic fillers can also be used to enhance mechanical and thermal properties with BN, used in some substrates to increase thermal conductivity, another possible source of boron.

\section{B. Neutron flux attenuation by printed circuit boards}

A typical FR-4 PCB substrate comprising $40 \%$ by weight epoxy resin and $60 \%$ by weight "E"-grade glass fibre could be expected to contain between about $0.2 \%$ and about $0.3 \%$ ${ }^{10} \mathrm{~B}$ by weight, or of the order of $10^{19} \mathrm{~cm}^{-3}{ }^{10} \mathrm{~B}$ atoms on average through the thickness of the substrate, assuming a substrate density $\sim 2 \mathrm{~g} \mathrm{~cm}^{-1}$. With a cross-section for neutron absorption of $3.8 \times 10^{3} \mathrm{~b}$ at $25 \mathrm{meV}$, we might expect a thermal neutron attenuation coefficient of between about $0.44 \mathrm{~cm}^{-1}$ and about $0.88 \mathrm{~cm}^{-1}$ and a loss of between about $7 \%$ and about $13 \%$ in a typical FR-4 substrate with overall thickness $1.6 \mathrm{~mm}$. By comparison, a ${ }^{10} \mathrm{~B}_{4} \mathrm{C}$ converter layer, with density $3.2 \mathrm{~g} \mathrm{~cm}^{-3}$ and optimum thickness $2.5 \mu \mathrm{m}$ [1], [8], [9], has an attenuation coefficient $578 \mathrm{~cm}^{-1}$ and absorbs about $13 \%$ of incident neutrons at $25 \mathrm{meV}$. According to this analysis, inadvertent absorption in circuit boards is likely to be similar in magnitude to desirable absorption in converter layers.

Bellinger at al. [10] described semiconductor thermal neutron detectors mounted on electronics assemblies, and reported an efficiency of $6.8 \%$ compared to the expected $18.9 \%$, a reduction of $\sim 64 \%$. They attributed this discrepancy in part to absorption in FR-4 circuit boards, reporting measured attenuation of $16.8 \%$ for a board on a $0.8 \mathrm{~mm}$ FR-4 substrate and $28.7 \%$ for a board on a $1.6 \mathrm{~mm}$ substrate. The full details 
of this experiment are not clear from [10] but it appears that the boards were populated and irradiated in a monoenergetic neutron beam at $25 \mathrm{meV}$.

Hoshor et al. [11] exploited absorption in FR-4 in a spectrometer design, quoting absorption of $16 \%$ in $0.8 \mathrm{~mm}$ FR-4 boards and attributing this to bromine as well as boron. This estimate of $16 \%$ appears to come from the same measurements reported in [10].

The cross-section for thermal neutron absorption by bromine is $\sim 11 \mathrm{~b}$ for ${ }^{79} \mathrm{Br}, \sim 2 \mathrm{~b}$ for ${ }^{81} \mathrm{Br}$, and $\sim 7 \mathrm{~b}$ for natural bromine, compared to $\sim 3.8 \times 10^{3} \mathrm{~b}$ for ${ }^{10} \mathrm{~B}$ and $\sim 0.8 \times 10^{3} \mathrm{~b}$ for natural boron [12]. Typical molar fractions of boron and bromine in FR-4 are expected to be similar; roughly $1 \%-2 \%$ for boron and about $4 \%$ for bromine. Thus bromine, where present, is likely to contribute no more than a few percent to the total absorption.

Recently, Scheuer et al. [13] investigated radiation effects on FR-4 circuits, attributed mostly to neutron reactions on ${ }^{10} \mathrm{~B}$ with some neutron capture by bromine also observed. They reported modest changes in electrical and mechanical properties after exposing samples to a total neutron fluence of the order of $10^{16} \mathrm{n} \mathrm{cm}^{-2}$.

In addition to absorption we expect neutrons to scatter, especially off hydrogen in the resin. Elastic scattering is the dominant neutron interaction with ${ }^{1} \mathrm{H}$, with a cross-section $\sim 30 \mathrm{~b}$ at thermal energies. A typical brominated resin is expected to have a molar fraction of hydrogen of $25 \%$ or more. Of the other elements found in typical circuit boards, oxygen and carbon have molar fractions in the range from $\sim 20 \%$ to $\sim 30 \%$ but significantly lower scattering cross-sections than hydrogen and are therefore not expected to contribute significantly to scattering. Depending on printed-circuit design, significant amounts of copper might be present and might affect scattering; thermal-neutron scattering cross-sections are $\sim 9.6 \mathrm{~b}$ for ${ }^{63} \mathrm{Cu}$ and $\sim 16 \mathrm{~b}$ for ${ }^{65} \mathrm{Cu}(\sim 12 \mathrm{~b}$ for natural $\mathrm{Cu})$.

Aside from its normal use as a printed circuit substrate, several groups have considered FR-4 for structural support in gas detectors, including for thermal neutrons [14], [15]. Absorption and, especially, scattering by the substrate have been recognised as disadvantages of FR-4 leading to preference for alternative materials such as aluminium and ceramics.

There are also published studies on absorption and scattering of neutrons at energies above $1 \mathrm{MeV}$ by circuits and circuit boards, in the context of evaluating neutron single-event effects [16], [17], [18], [19], [20]. In particular, Cazzaniga et al. [19] and Wender et al. [20] have reported measurements showing that single circuit boards can attenuate spallation neutron beams by $\sim 4 \%$.

\section{CURRENT WORK}

\section{A. Experiment}

A prototype detector assembly was exposed to a collimated source of thermal neutrons at the UK National Physical Laboratory [21], [22], [23]. The source is driven by a $2.8 \mathrm{MeV}$ deuteron beam striking beryllium targets. Fast neutrons from the $\mathrm{d}\left({ }^{9} \mathrm{Be},{ }^{10} \mathrm{~B}\right) \mathrm{n}$ reaction are moderated by a large graphite

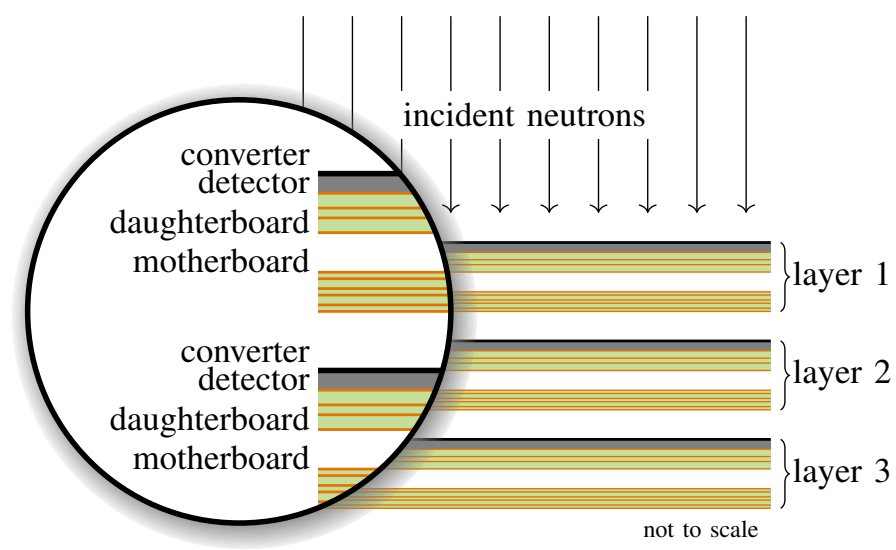

Fig. 1: Schematic arrangement of detectors, daughterboards and motherboards in relation to the incident neutrons during irradiation

block and reach the irradiation position through a cadmiumlined collimator. The moderated field is Maxwellian with temperature slightly above ambient $(\sim 27 \mathrm{meV})$ with an epithermal component with $1 / E$ energy-dependance. About $20 \%$ of the total fluence is above $0.5 \mathrm{eV}$. Measurements were made a fluence rate of $2 \times 10^{2} \mathrm{n} \mathrm{cm}^{-2} \mathrm{~s}^{-1}$.

The prototype assembly comprised three closely spaced motherboard layers each with an array of detectors mounted on daughterboards. The detectors [1] were planar $\mathrm{SiC}$ p-n diodes with a $\mathrm{B}_{4} \mathrm{C}$ converter layer enriched in ${ }^{10} \mathrm{~B}$. Neutron detection is via the $n\left({ }^{10} \mathrm{~B},{ }^{7} \mathrm{Li}\right) \alpha$ reaction, emitting an $\alpha$ particle and a ${ }^{7} \mathrm{Li}$ ion with energies $1.47 \mathrm{MeV}$ and $0.84 \mathrm{MeV}$, respectively, (94\% branching ratio) and $1.78 \mathrm{MeV}$ and $1.01 \mathrm{MeV}$, respectively, $(6 \%)$. The thickness of the converter layer was $2.5 \mu \mathrm{m}$; this is close to the optimum thickness determined by the range of the $1.47 \mathrm{MeV} \propto$ [1], [8], [9]. Each board was built on FR-4 substrate; motherboards were nominally $1 \mathrm{~mm}$ thick with 6 copper layers while the daughterboards were nominally $1 \mathrm{~mm}$ thick with 4 copper layers. The boards were arranged such that neutrons incident on the third detector layer had passed through two extra circuit boards, including one detector converter layer, compared to those incident on the second detector layer which was itself shielded from the first detector layer by two further circuit boards and one converter layer. Between each layer of detectors, therefore, there was an estimated $1.3 \mathrm{~mm}$ FR-4 and $2.5 \mu \mathrm{m}{ }^{10} \mathrm{~B}_{4} \mathrm{C}$ which together might be expected to reduce neutron flux by between about $18 \%$ and $23 \%$. This arrangement is shown schematically in Fig. 1.

Pulse height spectra were captured using a Kromek K102 multichannel analyser. Fig. 2a shows captured pulse-height spectra from the full beam (which contains both thermal and epithermal neutrons) compared to those from background measurements (made with the deuteron beam shut off) and measurements of epithermal neutrons alone (made with a $1 \mathrm{~mm}$ cadmium filter removing essentially all neutrons below $0.5 \mathrm{eV}$ ). The spectra in Fig. 2a are shown after quadratic LOESS smoothing over 16 channels to suppress random variations between channels. Fig. 2b shows the corresponding reverse cumulative spectra. The background signal is dominated by 


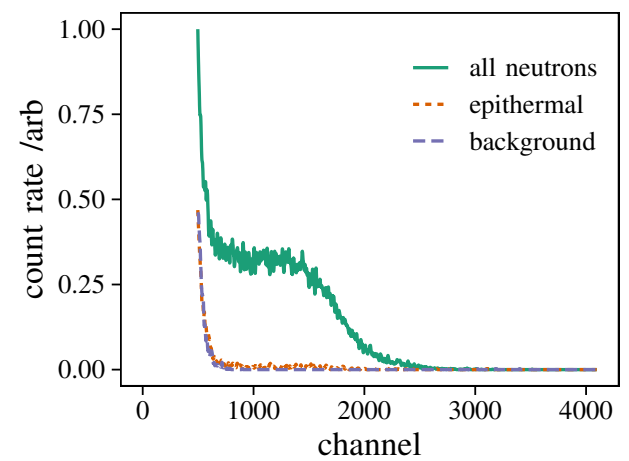

(a) Pulse-height spectra

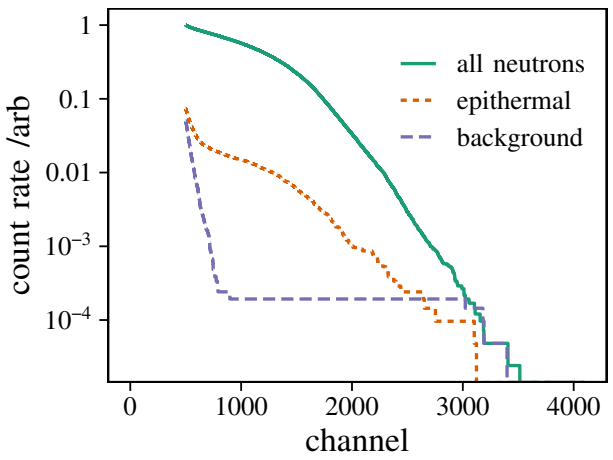

(b) Reverse cumulative pulse-height spectra

Fig. 2: Measured pulse-height spectra

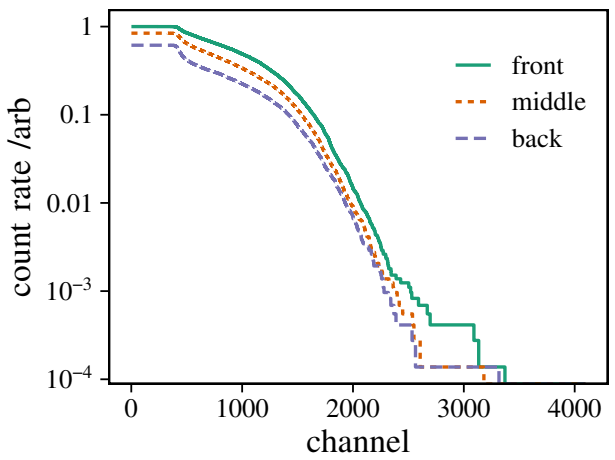

Fig. 3: Measured reverse cumulative pulse-height spectra for front, middle and back boards

electrical noise while the epithermal contribution is an order of magnitude lower than the thermal contribution.

Setting a detection threshold at channel 1000, the effect of two intervening circuit boards was to reduce average detection rate by $0.32 \pm 0.01$. This represents about one third, which is somewhat more than expected. This value varies only slightly with threshold, as shown by Fig. 3 .

\section{B. Simulation}

We did simulations using MCNP 6.2 [24] to evaluate the likely effect of FR-4 substrates on neutron flux attenuation. The glass component was modelled in three variants: with high and low boron content as well as a boron-free variant,
TABLE I: E-glass composition, as modelled, percentage by weight

\begin{tabular}{lccc}
\hline & low-boron & high-boron & boron-free \\
\hline $\mathrm{B}_{2} \mathrm{O}_{3}$ & 5 & 10 & 0 \\
$\mathrm{SiO}_{2}$ & 54 & 54 & 56 \\
$\mathrm{CaO}$ & 22 & 17 & 24 \\
$\mathrm{Al}_{2} \mathrm{O}_{3}$ & 14 & 14 & 15 \\
$\mathrm{Fe}_{2} \mathrm{O}_{3}$ & 0.2 & 0.2 & 0.2 \\
$\mathrm{MgO}$ & 3 & 3 & 3 \\
$\mathrm{Na}_{2} \mathrm{O}$ & 0.8 & 0.8 & 0.8 \\
$\mathrm{~F}_{2}$ & 0.5 & 0.5 & 0.5 \\
$\mathrm{TiO}_{2}$ & 0.5 & 0.5 & 0.5 \\
\hline
\end{tabular}

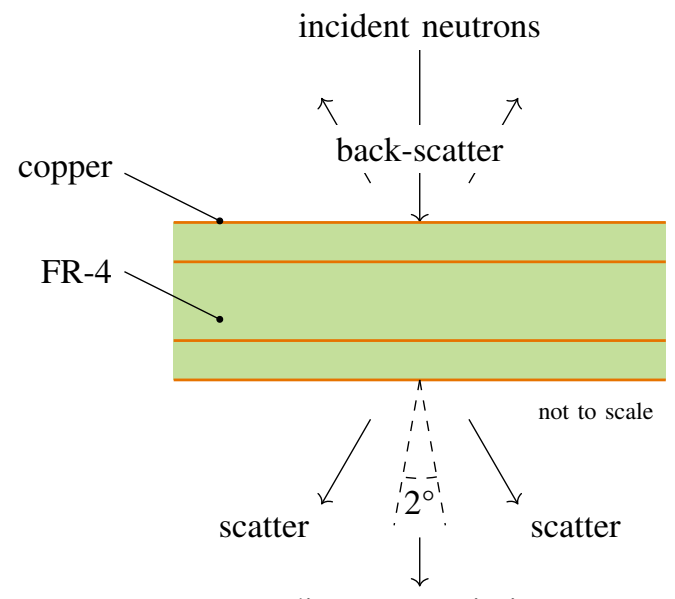

direct transmission

Fig. 4: Schematic arrangement of simulation geometry

as specified in Table I. Following Zaffora and Magistris [5], the resin component was modelled as having atomic ratio 18:24:3:4 C:H:O:B. The resin:glass ratio was assumed to be 40:60 by weight, while density was assumed to be $1.1 \mathrm{~g} \mathrm{~cm}^{-3}$ and $2.5 \mathrm{~g} \mathrm{~cm}^{-3}$ for resin and glass, respectively, and $1.94 \mathrm{~g} \mathrm{~cm}^{-3}$ for the composite material. Observe that in this case the model represents the PCB substrate as containing $26 \% \mathrm{H}, 4 \% \mathrm{Br}$, and up to $0.6 \%{ }^{10} \mathrm{~B}$, by atom.

In the simulations, thermal neutrons from a collimated Maxwellian distribution at temperature $25.3 \mathrm{meV}$ were normally incident on semi-infinite slabs of thickness between $0.8 \mathrm{~mm}$ and $3.2 \mathrm{~mm}$. Neutrons passing through the far surface and those scattering back through the near surface were tallied separately. Those passing through the far surface within $1^{\circ}$ of normal were considered to be directly transmitted, those passing through at more than $1^{\circ}$ off normal were considered scattered. Fig. 4 shows this arrangement schematically; an example MCNP input deck is given in the Appendix.

Example simulation results are given in Fig. 5, which shows the brightness of the neutron flux emerging from typical 40:60 brominated resin:high-boron glass substrates; that is, the number of neutrons emerging per unit solid angle in a direction of interest. In particular, the first bin in the forward direction, which forms a cone normal to the surface with semi-angle $1^{\circ}$, encloses a solid angle of $9.6 \times 10^{-4} \mathrm{sr}$, such that a brightness in this specific bin of, for example, $500 \mathrm{n} \mathrm{sr}^{-1}$ represents a transmission of $\sim 50 \%$ (mutatis mutandis, in proportion). For 


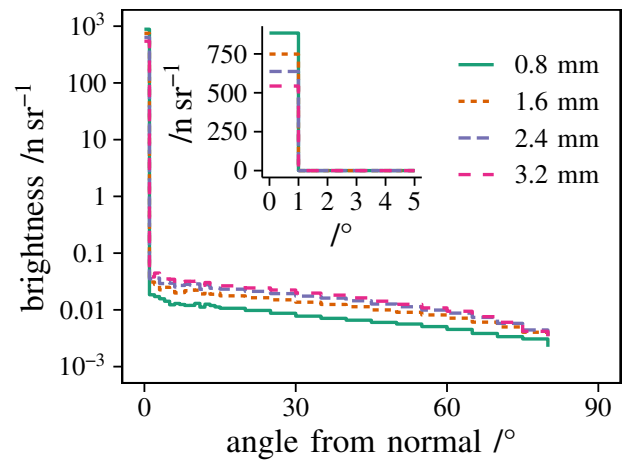

(a) Transmission

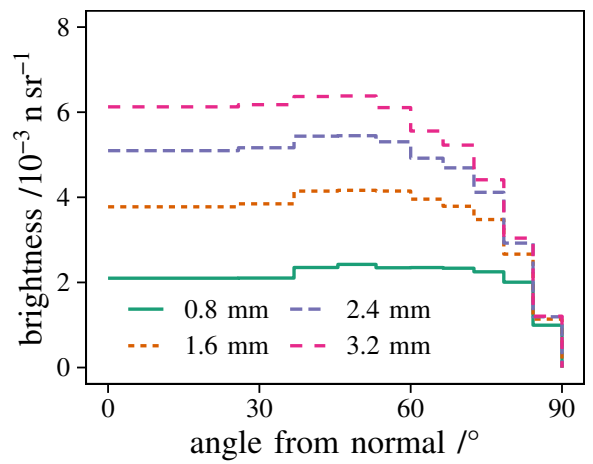

(b) Back-scatter

Fig. 5: Effect of substrate thickness on simulated neutron brightness per incident neutron of FR-4 with high-boron glass

example, for the case of the $1.6 \mathrm{~mm}$ substrate, approximately $72 \%$ of incident neutrons are transmitted with divergence $1^{\circ}$ or less, $5 \%$ are scattered through more than $1^{\circ}$ in the forward direction, $2 \%$ are scattered backwards and $21 \%$ are absorbed. Both scattering and absorption increase as substrate thickness increases.

Fig. 6 shows the effect of boron content in $1.6 \mathrm{~mm}$ substrates. In the boron-free case, direct transmission (i.e. divergence by no more than $1^{\circ}$ ) is increased to $89 \%$. The proportion of incident neutron flux that is scattered out of the board is $7 \%$ in the forward direction and $3 \%$ backwards. Absorption in this case is reduced to $0.5 \%$, which is consistent with a simple model for absorption by other constituent elements which gives an estimated attenuation coefficient $0.03 \mathrm{~cm}^{-1}$ (of which bromine is responsible for about $70 \%$ and hydrogen for about 20\%) and an estimated absorption in $1.6 \mathrm{~mm}$ (i.e. neglecting increased path length due to scattering) of $0.5 \%$.

Fig. 7 shows results from simulations with and without copper planes. The case with copper has two internal copper planes, each $35 \mu \mathrm{m}$ thick, representing typical power-planes in a multi-layer board. This is the case defined by the MCNP input card given in the Appendix. Typically thin copper layers such as these are predicted to have little effect on neutron scattering and attenuation.

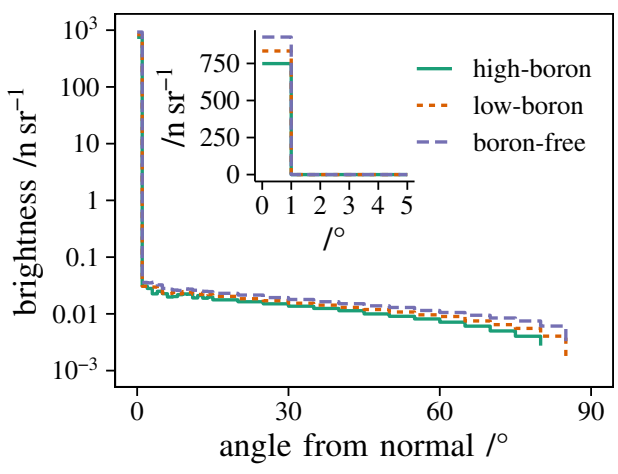

(a) Transmission

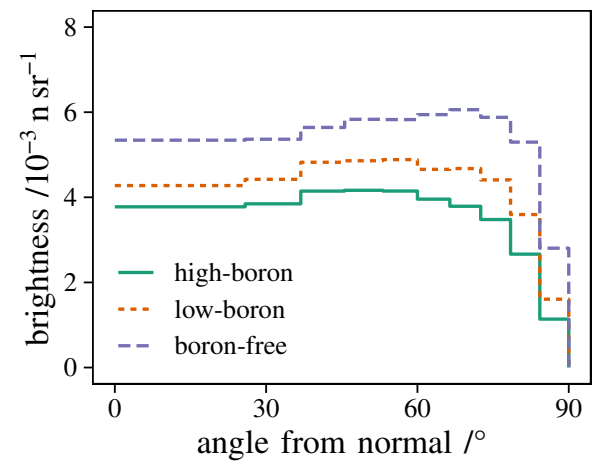

(b) Back-scatter

Fig. 6: Effect of boron content on simulated neutron brightness per incident neutron of $1.6 \mathrm{~mm}$ FR-4

\section{Measured and modelled attenuation}

Fig. 8 shows a comparison between simulated and measured transmission of thermal neutrons through printed circuit boards. Simulation results are for 40:60 resin:glass FR-4 substrates; the shading encompasses results for low-boron and high-boron glass. Direct transmission, that is, of the portion of collimated beams that diverges by less than $1^{\circ}$, is described by an attenuation coefficient $2.1 \mathrm{~cm}^{-1}$ in the high-boron case and $1.4 \mathrm{~cm}^{-1}$ in the low-boron case. Total transmission, including that scattered through more than $1^{\circ}$, is described by attenuation coefficients $1.6 \mathrm{~cm}^{-1}$ (high-boron) and $1.0 \mathrm{~cm}^{-1}$ (low-boron). By comparison, the simulated attenuation coefficients assuming boron-free glass (not shown in Fig. 8) are $0.8 \mathrm{~cm}^{-1}$ (direct) and $0.2 \mathrm{~cm}^{-1}$ (total).

Measured data for FR-4 are for transmission through populated circuit boards in collimated thermal neutron beams, from this work and from Bellinger et al. [10]. The value shown for this work is corrected for absorption through $2.5 \mu \mathrm{m}$ ${ }^{10} \mathrm{~B}_{4} \mathrm{C}$ and represents $78 \%$ total transmission through $\sim 1.3 \mathrm{~mm}$ FR-4. Measurements on polyimide are for total transmission through two samples of unpopulated rigid boards (thickness $1.5 \mathrm{~mm}$ and $1.6 \mathrm{~mm}$ ), measured under a different configuration in which neutrons were generated from a moderated californium source. Dissimilar experimental conditions complicate direct comparison with measurements made on populated FR-4 boards in collimated beams of thermal neutrons. Nonetheless, there is also significant absorption in the polyimide boards, 


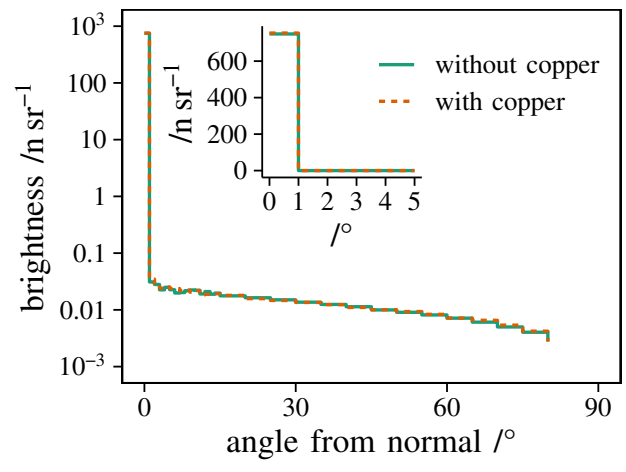

(a) Transmission

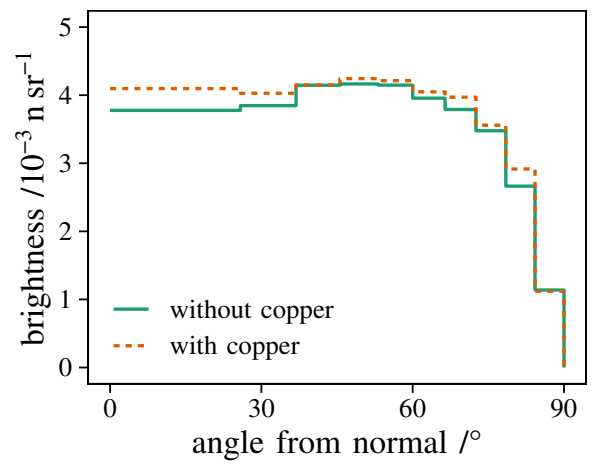

(b) Back-scatter

Fig. 7: Effect of copper layers on simulated neutron brightness per incident neutron of $1.6 \mathrm{~mm}$ FR-4

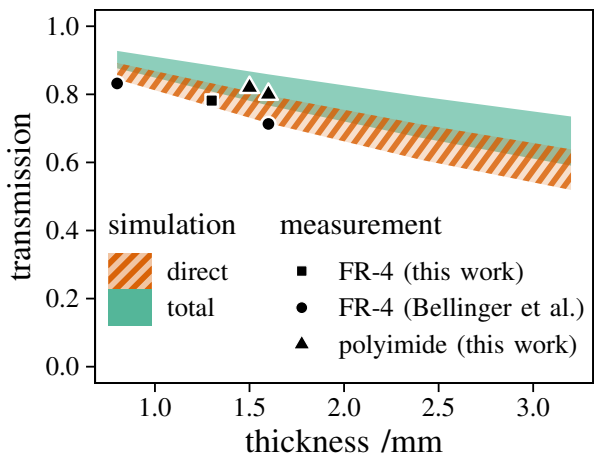

Fig. 8: Measured and simulated thermal neutron transmission through printed circuit boards. Simulation results are for 40:60 resin:glass FR-4; the shading encompasses results for lowboron and high-boron glass.

with measured attenuation coefficient $1.3 \mathrm{~cm}^{-1}$ or $1.4 \mathrm{~cm}^{-1}$.

\section{DISCUSSION}

Simulated direct transmission of normally incident thermal neutrons through FR-4 predicts attenuation coefficients in the range from $1.4 \mathrm{~cm}^{-1}$ to $2.1 \mathrm{~cm}^{-1}$, depending on boron content. This is two or three times as much as simple estimates based on the neutron absorption cross-section for ${ }^{10} \mathrm{~B}$, which are in the range from $0.44 \mathrm{~cm}^{-1}$ to $0.88 \mathrm{~cm}^{-1}$. We attribute the excess to scattering, especially off hydrogen in the resin. Furthermore, as scattered neutrons follow longer paths through the substrate they are preferentially absorbed by boron leading to attenuation of the total transmission (direct and scattered, combined) in the range from $1.0 \mathrm{~cm}^{-1}$ to $1.6 \mathrm{~cm}^{-1}$. This deleterious synergy is similar in principle to that in which back-scattering is exploited to advantage in applications including neutron detection [25] and neutron depth profiling [26]. The influence of other circuitboard materials, including copper, does not seem to be significant.

The results of our simulations are consistent with measurements made in collimated thermal neutron beams, both in this work and as reported elsewhere [10]. This is despite the simulations' not accounting for any effect of packaged parts on populated boards (in particular, plastic packages, connectors, etc. would be expected to increase scattering). Measurements of samples of rigid polyimide PCB substrate materials show attenuation which, although slightly lower than the results of measurements on populated FR-4 PCBs, is nonetheless within the range of uncertainty due to the range of boron concentrations in ' $E$ '-glass fibre, which the polyimide boards are also understood to contain.

Fast neutron attenuation in circuit boards is much less. Cazzaniga et al. [19] measured broadband absorption of fast neutrons in FR-4 and reported an attenuation coefficient of $\sim 0.06 \mathrm{~cm}^{-1}$, consistent with MCNPX simulation results and corresponding to $\sim 99 \%$ transmission though $1.6 \mathrm{~mm}$ of FR-4. Similarly, Wender et al. [20] measured energy-dependent transmission of fast neutrons though populated circuit boards. They reported generally decreasing attenuation as energy increased above $1 \mathrm{MeV}$ and transmission through a single $2.5 \mathrm{~mm}$ populated board of $\sim 95 \%$ at $10 \mathrm{MeV}$. Consistent with this, our own MCNP simulations predict direct and total transmission through $1.6 \mathrm{~mm}$ of representative high-boron FR-4 of 94\% and $98 \%$, respectively, at $1 \mathrm{MeV}$ and $98 \%$ and $99 \%$ at $10 \mathrm{MeV}$. At $100 \mathrm{MeV}$ our simulations predict direct transmission to be $99 \%$ and that neutron multiplication leads to a small net increase in total neutron current emerging from the board.

One of the limitations of our MCNP simulations is that material specifications such as that shown in the Appendix assume a free-gas representation in which individual atoms are unbound. At low energies this does not properly represent energy and momentum transfer during neutron scattering in molecular materials. In our case we expect scattering to be dominated by the hydrogen content of the resin. Scattering law ("S $(\alpha, \beta)$ ") data are available for some materials but not for the epoxy resin of particular interest here (and whose composition is, in any case, uncertain). Scattering law data are available for polyethylene $\left(\mathrm{C}_{2} \mathrm{H}_{4}\right)$ however [27], and this has been considered here as a possible proxy for the epoxy resin.

Fig. 9 shows the brightness of a $0.5 \mathrm{~mm}$ semi-infinite slab of polyethylene [28] as simulated with and without the scattering law. The results excluding the scattering law are quantitatively similar to those for the boron-free case (cf. Fig. 6) and show a transmission of $88 \%$ and scattering of $8 \%$ and $3 \%$ in forwards and backwards directions, respectively. When the scattering law is included, simulated scattering increases to 


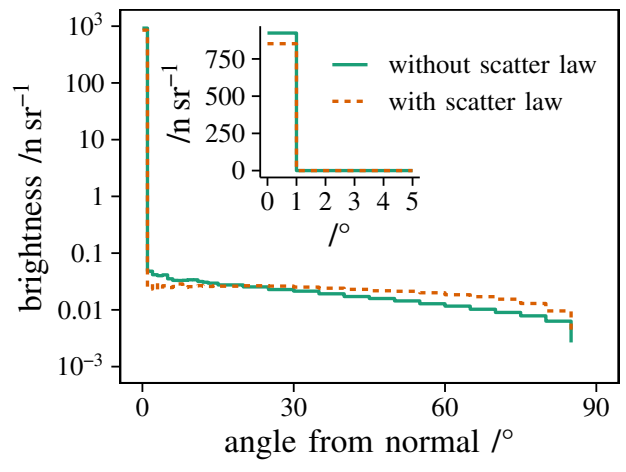

(a) Transmission

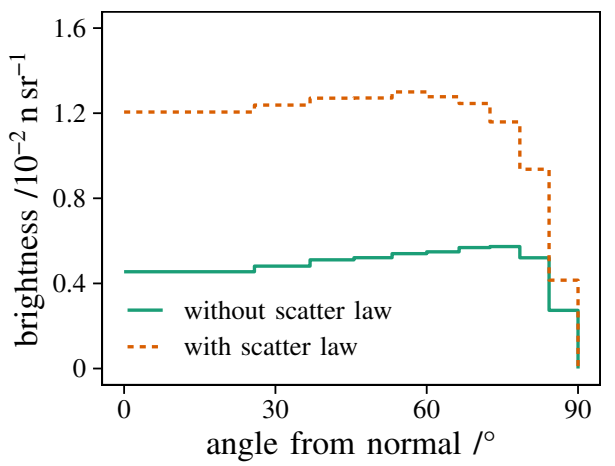

(b) Back-scatter

Fig. 9: Effect of scatter law on simulated neutron brightness per incident neutron of $0.5 \mathrm{~mm}$ polyethylene

$11 \%$ (forwards) and 7\% (backwards) with direct transmission reducing to $81 \%$. Absorption is negligible in either case.

These results suggest that our simulations of FR-4 may slightly underestimate scattering and slightly overestimate transmission. Nonetheless, we think that the main uncertainty in these results is in the FR-4 material composition and that the attenuation coefficient $2.1 \mathrm{~cm}^{-1}$ is close to the worst-case for normally-incident thermal neutrons. Conservatively, an attenuation coefficient of $2 \mathrm{~cm}^{-1}$ corresponds to attenuation $27 \%$ by $1.6 \mathrm{~mm}$ of FR-4 substrate, more than twice that predicted from absorption due to ${ }^{10} \mathrm{~B}$ in the absence of significant scattering and also more than twice that due to absorption in an optimum $\mathrm{B}_{4} \mathrm{C}$ converter layer (see Section I-B). We also expect a secondary effect whereby the lowest-energy neutrons are preferentially extracted from the neutron field because of the energy-dependence of the cross-sections both for elastic scattering off hydrogen and for capture by boron, further reducing detector efficiency by a small amount.

\section{CONCLUSION}

Our results show how thermal neutron transmission through printed circuit boards is affected by scattering, especially off hydrogen, and absorption, especially by ${ }^{10} \mathrm{~B}$ in the borated ' $\mathrm{E}$ 'glass typically used in FR-4 and rigid polyimide boards. Attenuation coefficients can be as high as $2 \mathrm{~cm}^{-1}$, corresponding to $27 \%$ attenuation by $1.6 \mathrm{~mm}$ of substrate, and can be as much as twice that due to optimised neutron converter layers in thermal neutron detectors. Design of detector assemblies should take this attenuation into account and may require board thickness to be minimised or specialised substrates to be used, for example excluding borated fibreglass reinforcement.

\section{REFERENCES}

[1] S. D. Monk, S. P. Platt, M. J. Anderson, M. Alhamdi, and D. Cheneler, "Development of an optimized converter layer for a silicon-carbide-based neutron sensor for the detection of fissionable materials," in 2019 Nucl. Sci. Symp. Conf. Record, 2019.

[2] C. F. Coombs and H. Holden, Eds., Printed Circuits Handbook, 7th ed. McGraw Hill, 2016.

[3] Specification for finished fabric woven from " $E$ " glass for printed boards, IEC Std. IEC/PAS 61 249-6-3:2011, 2011.

[4] Specification for Finished Fabric Woven from " $E$ "' Glass for Printed Boards, IPC Std. IPC-4412A, Jan. 2006.

[5] B. Zaffora and M. Magistris, "Radiological characterization of printed circuit boards for future elimination," Applied Radiation and Isotopes, vol. 113 , pp. 40-46, Jul. 2016.

[6] D. T. Haworth and G. F. Pollnow, "Boron curing agents for epoxy resins," Industrial \& Engineering Chemistry Product Research and Development, vol. 1, no. 3, pp. 185-187, Sep. 1962.

[7] M. J. Mullins, D. K. Luttrull, and H. Schumacher, "Boric acid in PCBs: compliance with EU REACH regulations," Circuit World, vol. 37, no. 4, pp. 16-19, Nov. 2011.

[8] D. S. McGregor, M. D. Hammig, Y.-H. Yang, H. K. Gersch, and R. T. Klann, "Design considerations for thin film coated semiconductor thermal neutron detectors - I: basics regarding alpha particle emitting neutron reactive films," Nucl. Instrum. Methods Phys. Res. A, vol. 500, no. 1-3, pp. 272-308, Mar. 2003.

[9] F. Piscitelli, J. C. Buffet, J. F. Clergeau, S. Cuccaro, B. Guérard, A. Khaplanov, Q. L. Manna, J. M. Rigal, and P. V. Esch, "Study of a high spatial resolution ${ }^{10} \mathrm{~B}$-based thermal neutron detector for application in neutron reflectometry: the Multi-Blade prototype," J. Instrum., vol. 9, no. 3, p. P03007, Mar. 2014.

[10] S. L. Bellinger, R. G. Fronk, T. J. Sobering, and D. S. McGregor, "Highefficiency microstructured semiconductor neutron detectors that are arrayed, dual-integrated, and stacked," Applied Radiation and Isotopes, vol. 70, no. 7, pp. 1121-1124, Jul. 2012.

[11] C. Hoshor, T. Oakes, E. Myers, B. Rogers, J. Currie, S. Young, J. Crow, P. Scott, W. Miller, S. Bellinger, T. Sobering, R. Fronk, J. Shultis, D. McGregor, and A. Caruso, "A portable and wide energy range semiconductor-based neutron spectrometer," Nucl. Instrum. Methods Phys. Res. A, vol. 803, pp. 68-81, Dec. 2015.

[12] Evaluated nuclear data file (ENDF). Database. International Atomic Energy Agency. [Online]. Available: https://www-nds.iaea.org/exfor/ endf.htm

[13] K. Scheuer, J. Holmes, E. Galyaev, D. Blyth, and R. Alarcon, "Radiation effects on FR4 printed circuit boards," IEEE Trans. Nucl. Sci., vol. 67, no. 8, pp. 1846-1851, Aug. 2020.

[14] F. Piscitelli, F. Messi, M. Anastasopoulos, T. Bryś, F. Chicken, E. Dian, J. Fuzi, C. Höglund, G. Kiss, J. Orban, P. Pazmandi, L. Robinson, L. Rosta, S. Schmidt, D. Varga, T. Zsiros, and R. Hall-Wilton, "The multi-blade boron-10-based neutron detector for high intensity neutron reflectometry at ESS," J. Instrum., vol. 12, no. 3, p. P03013, Mar. 2017.

[15] J. Zhou, X. Zhou, J. Zhou, X. Jiang, J. Yang, L. Zhu, W. Yang, T. Yang, H. Xu, Y. Xia, G. an Yang, Y. Xie, C. Huang, B. Hu, Z. Sun, and Y. Chen, "A novel ceramic GEM used for neutron detection," Nucl. Engin. Technol., vol. 52, no. 6, pp. 1277-1281, Jun. 2020.

[16] P. Truscott, C. Dyer, A. Frydland, A. Hands, S. Clucas, and K. Hunter, "Neutron energy-deposition spectra measurements, and comparisons with Geant4 predictions," IEEE Trans. Nucl. Sci., vol. 53, no. 4, pp. 18831889, Aug. 2006.

[17] S. Platt and Z. Torok, "Analysis of SEE-inducing charge generation in the neutron beam at The Svedberg Laboratory," IEEE Trans. Nucl. Sci., vol. 54, no. 4, pp. 1163-1169, Aug. 2007.

[18] T. Kato, R. Akano, T. Uemura, Y. Watanabe, and H. Matsuyama, "Neutron shielding effect of stacked servers and its impact on reduction of soft error rate," IEEE Trans. Nucl. Sci., vol. 61, no. 6, pp. 3408-3415, Dec. 2014.

[19] C. Cazzaniga, B. Bhuva, M. Bagatin, S. Gerardin, N. Marchese, and C. D. Frost, "Atmospheric-like neutron attenuation during accelerated neutron testing with multiple printed circuit boards," IEEE Trans. Nucl. Sci., vol. 65, no. 8, pp. 1830-1834, Aug. 2018. 


\section{APPENDIX \\ EXAMPLE MCNP INPUT DECK}

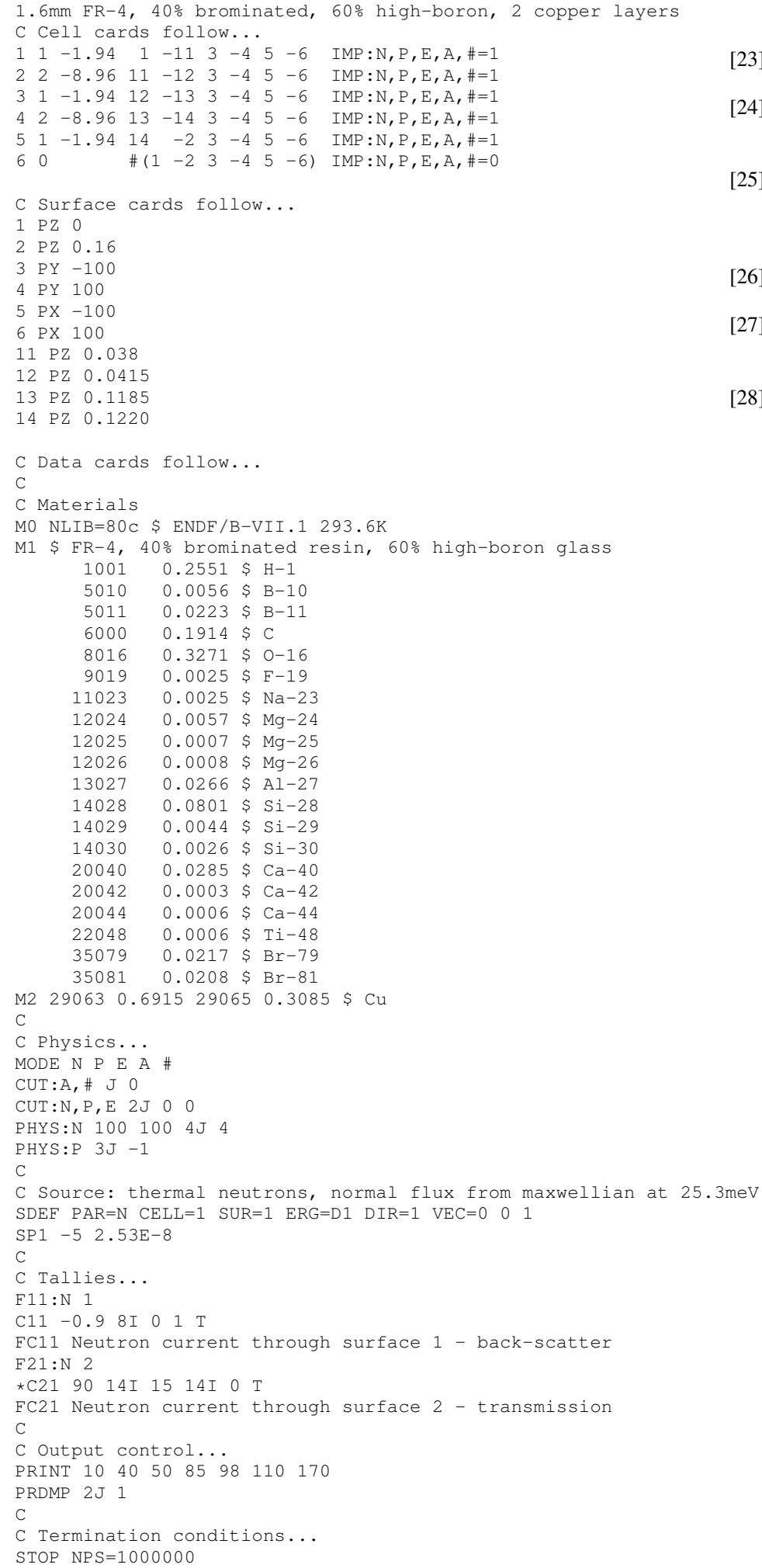

